“ (C) 2017 IEEE. Personal use of this material is permitted. Permission from IEEE must be obtained for all other uses, in any current or future media, including

reprinting/republishing this material for advertising or promotional purposes, creating new collective works, for resale or redistribution to servers or lists, or reuse of any copyrighted component of this work in other works." 


\title{
Design and Analysis of Protection Circuits for Safe Operation of Direct Matrix Converters
}

\author{
Zahra Malekjamshidi, Mohammad Jafari, Member, IEEE and Jianguo Zhu, Senior Member, IEEE \\ Faculty of Engineering and Information Technology, University of Technology Sydney \\ PO Box 123, Broadway, NSW 2007, Australia \\ Zahra.Malekjamshidi@student.uts.edu.au
}

\begin{abstract}
This paper is concerned with the process of current commutation and overvoltage protection in matrix converters. The mechanisms involved in the commutation process and clamp circuit are described and simulation waveforms are presented. A four-step semi-soft commutation strategy is described that this technique relies on knowledge of the output current direction and the ability to control the direction of current within the switches. Also a clamp circuit is demonstrated by simulation as an overvoltage protection for matrix converter. Simulation results are presented using a simulation model of the three-phase direct matrix converter in MATLAB/Simulink.
\end{abstract}

Index Terms-Direct matrix converter, switch commutation, overvoltage protection, clamp circuit, numerical simulation.

\section{INTRODUCTION}

D UE to the recent attention to the renewable energy systems, various distributed generation (DG) systems, micro-grid structures and converter topologies are proposed in the literatures [1]-[3]. Although some of the renewable resources such as solar and wind, have been used for many years, there is still a serious concern on their integration into the conventional distribution networks. This has emerged the concept of micro-grids and the energy transfer between the micro-grid and the utility network. Matrix converters can be used as bidirectional link between the ac micro-grid and the main grid to control the energy transfer and power flow effectively. The study of the matrix converter has been going on for the last 35 years. It is hoped that the AC-AC matrix converter topology will replace the traditional AC-DC-AC converters since common converters are bulky and costly. Matrix converters (MCs) are a group of AC-AC converters that connect directly a three-phase source to a three-phase load and are able to convert energy of the ac-source to variable output voltages with unrestricted frequency without using the bulky energy storage elements, which generally has limited lifetime. Recently, MCs have received extensive research attention in the variable voltage and variable frequency AC drive applications because of their distinctive advantages such as high quality sinusoidal input and output waveforms, adjustable input power factor, lack of bulky energy storage components and capability of regeneration [4]-[7]. The major disadvantage of MCs is limited voltage transfer ratio $(0.86)$.
There are some operational limitations in all matrix converter topologies. Because of the inductive characteristics of the load, if the path of the load current is cut for any reason, over voltage will occur in the output side thus the load current path must always be closed. Also to avoid input current spikes, the input source phases should never be short circuited, so that every output phases must be connected to an input phase at any instant.

On the other hand achieving the simultaneous commutation of controlled bidirectional switches used in direct matrix converter is very difficult without generating overcurrent or overvoltage spikes that are destructive for the power semiconductors. This fact used to be a limitation for practical implementation of the MCs and negatively affected the interest in this AC-AC converter. Fortunately, this major problem can be solved with the development of various multi-step commutation strategies that allow safe operation of the switches.

The remainder of paper is organized as follows. First, the basic switch commutation explanation will be given, and some general commutation for direct matrix converter will be mentioned. Four-step semisoft commutation strategy is analysed, and a general approach for clamp circuit design as overvoltage protection is proposed. Next, the simulation results are presented, and the functions are validated by simulation using MATLAB Simulink. Finally, conclusions are drawn in the last section.

\section{SWITCH COMMUTATIONS}

As there are no natural freewheeling paths in MCs, reliable current commutation between switches is more difficult to achieve than in conventional voltage source inverters. Common method in voltage source inverters is the dead-time method. The load current freewheels through the anti-parallel diodes during the dead-time period. In matrix converters, however, using dead-time commutation causes an open circuit in the load side that will result in large voltage spikes across the switches and could destroy the MC unless snubber or clamping circuits are used to provide a path for the load current during the dead-time period. In this method, the energy in the protection circuits is lost during every commutation. Fig. 1 shows the schematic of three-phase to three-phase direct matrix converter with input filter and three phase RL load. For safe switching, it is necessary that no two 


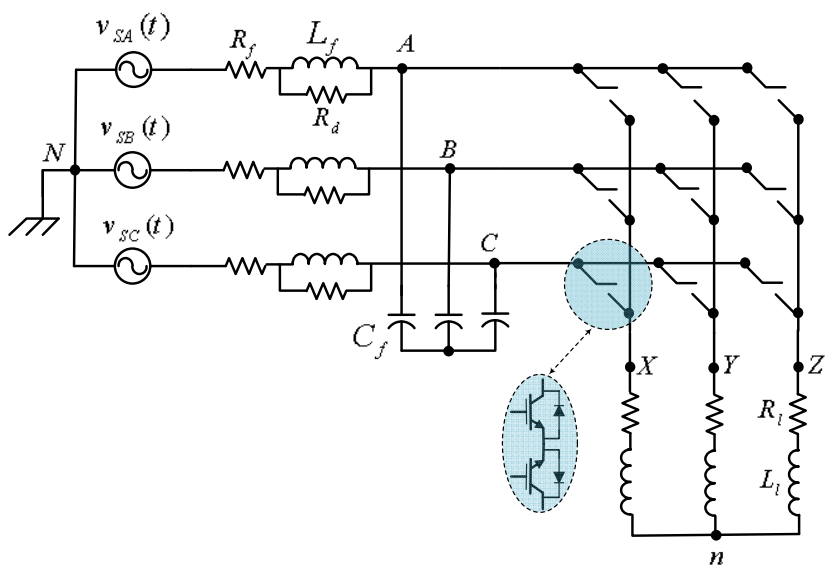

Fig. 1. A three-phase to three-phase AC-AC matrix converter

bi-directional switches of the MC connected to an output phase be turned on at the same time, because this might result in a line-to-line short circuit and could destroy the converter switches. In addition, the bi-directional switches connected to each output phase should not all be turned off at any instant, as creates an open circuit in the converter that results in the absence of a freewheeling path for the inductive load current, a large voltage spike that could destroy the switches. To prevent the commutation failure caused due to the practical limitation of the bidirectional switch, a special commutation strategy can be chosen for that purpose such as one, two or four-step commutations.

Information about the actual current direction in the involved output phase is necessary in four-step commutation strategy. Also, the two-step commutation method depends on the relative input voltages magnitude [12] and the one-step commutation depends on the knowledge of both the direction of load current and the relative input voltages [10].

\section{FOUR STEP COMMUTATION METHOD}

When the commutation of an output phase between any two input phases is required, it is not possible switching off a bidirectional-switch and switching on another bidirectionalswitch simultaneously due to the different propagation time delay of the gating signals and different turn-on and turn-off times of the IGBTs.

Fig. 2 shows connection of two phases of the input source to the first output phase to illustrate the commutation problem. If any bidirectional switches $S 11$ or $S 12$ are turned on before the other switch is turned off then a short circuit path is established and current spikes generated this way are destructive for the switches. Similarly, if any of the switches is turned off before the other switch is turned on, then an open circuit occurs in the output side and freewheeling path for the inductive load current is necessary, otherwise voltage spikes in the inductive load, will destroy the converter switches. In steady state, when the output phase is connected to an input phase both of the IGBTs in the active bidirectional switch have to be turned on to allow both directions of current flow. Due to the time required to turn on or off an IGBT, to avoid open circuit and short circuit and consequently avoiding over voltage and over current spikes, a number of commutation approaches have been proposed.

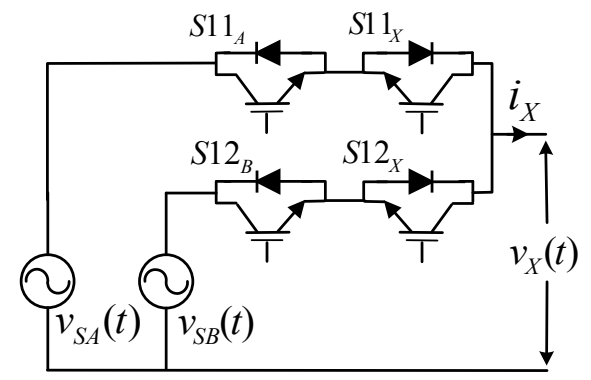

Fig. 2. A typical two-phase to single-phase converter circuit illustrating commutation between two bi-directional switches

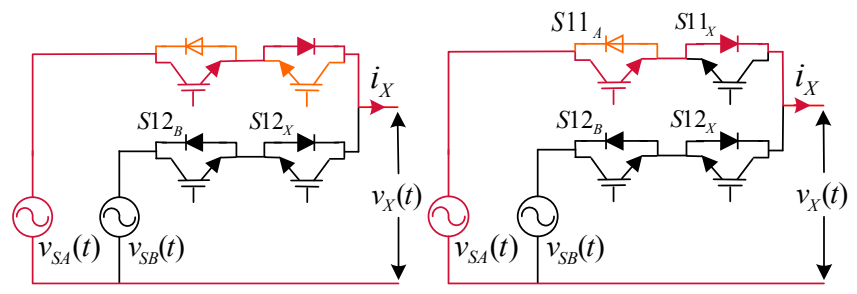

(a)

(b)

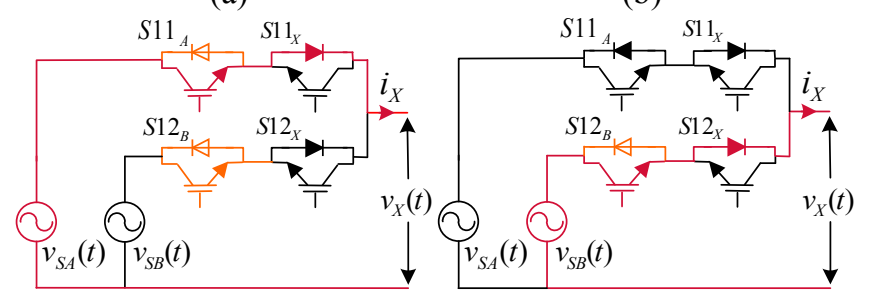

(c)

(d)

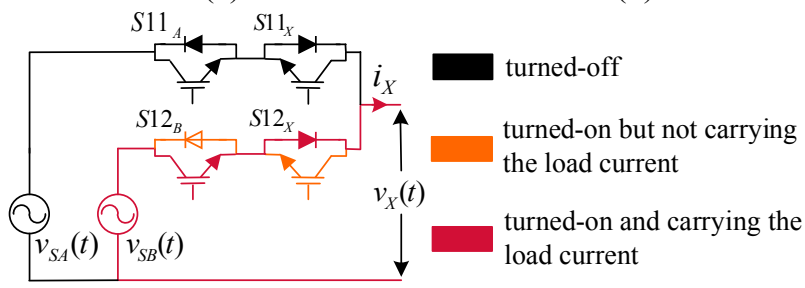

(e)

Fig. 3. The four-step semisoft current commutation (a) A steady state of the converter, where the load current is carried by switch $S 11$ (b) Step-1, turning off the idle switch $S 11_{X}$ (c) Step-2, turning on the incoming switch $S 12_{B}$ (d) Step-3, turning off the conducting switch $S 11_{A}$ (e) Step-four, turning on switch $S 12_{X}$ so that reverse current direction is possible, another steady state of the converter, where the load current is carried by $S 12$

These methods depend on the knowledge of a reliable load current direction or the relative input phase voltages magnitude. The commutation method that is presented is based on load current measurements and a circuit is needed to detect the direction of current flow within the bidirectional switches. This strategy does not rely on the matrix converter modulation algorithm [11]. The following explanation assumes that the load current is in the direction shown in Fig. 2 and at first the bidirectional switch $S 11$ is closed. When a commutation to $S 22$ is required, the current direction is needed to determine which IGBT in the active bidirectional switch is not carrying the load current. This device is then turned off. In this case $S 11_{X}$ is turned off. The device that will conduct the current in the incoming switch is then gated $\left(S 12_{B}\right.$ in this example) and the load current transfers to it when the outgoing device $\left(S 11_{A}\right)$ is turned off. The remaining device in the incoming switch $\left(S 12_{X}\right)$ is turned on so that a reverse direction is provided for the load current as shown in Fig.3. This process is illustrated as a timing diagram in Fig.4, 

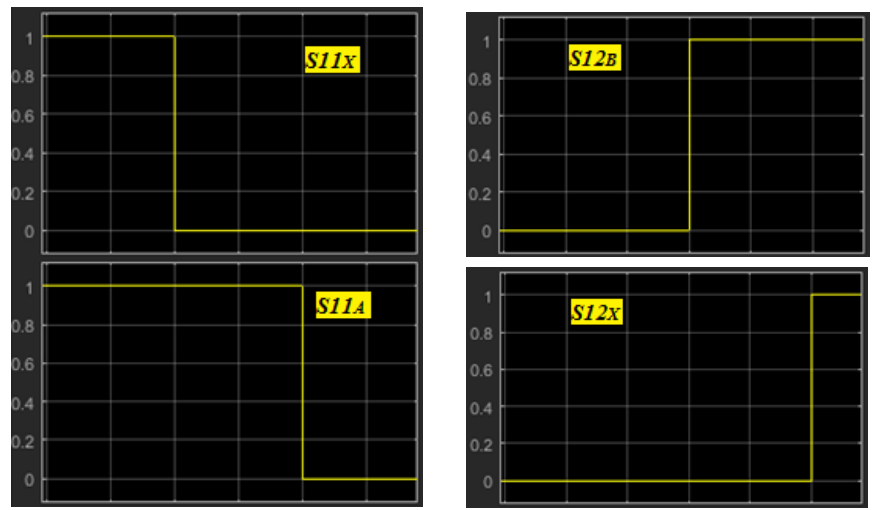

Fig. 4. Timing sequences of the four-step commutate method for $S 11$ and S12

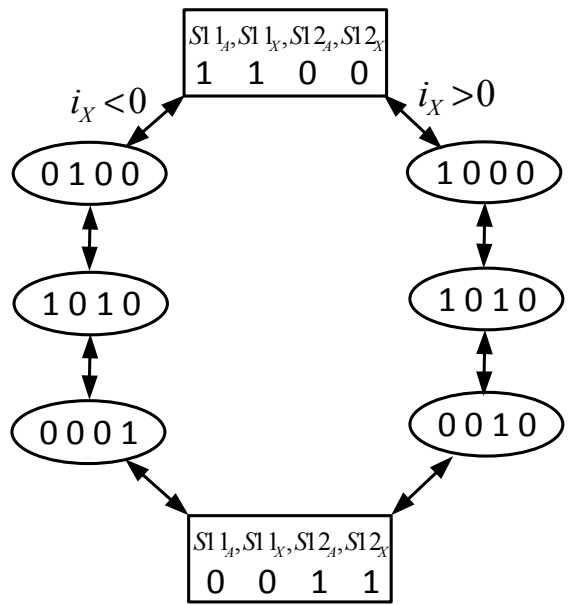

Fig. 5. Logic state diagram for one output phase, four-step commutation strategy

the delay between each switching event is determined by the device characteristics. Fig. 3 shows the general state diagram of the commutation strategy under the assumption that initially $S 11$ is on and $S 12$ is off.

\section{OVERVOLTAGE PROTECTION}

The matrix converter topology needs to be protected against overvoltage and overcurrent situations. Due to the lack of an energy storage element, this topology is more sensitive to disturbances and input source changes which may cause hardware failures. Any issue in switching commutation process would cause short circuit of the input source or disconnection of the load current. Possible overvoltage on the input side caused by the converter power-up and also turning off the matrix converter during an overcurrent event on the load side, are the other reasons of overvoltage. A clamp circuit protects the power converter switches from destruction when a fault occurs.

A typical clamp circuit for protection of a matrix converter is shown in Fig.6. The circuit consists of two rectifier bridges using six fast-recovery diodes at the input and output of the converter. The capacitor $C_{c}$ takes the commutation energy and the resistor $R_{c}$ can discharge the capacitor. The total energy stored in a three-phase inductance carrying sinusoidal balanced currents is calculated as:

$$
Q_{L}=\frac{1}{2} L\left(i_{x, r m s}^{2}+i_{y, r m s}^{2}+i_{z, r m s}^{2}\right)
$$

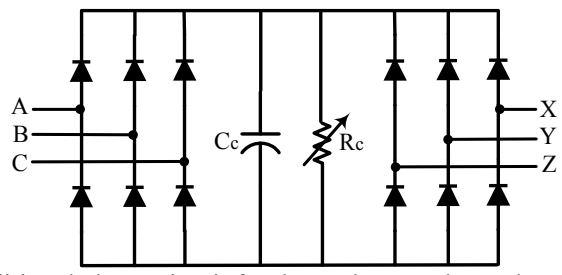

Fig. 6. A traditional clamp circuit for three-phase to three-phase direct matrix converter

TABLE I

POWER CIRCUIT PARAMETERS

\begin{tabular}{lr}
\hline Parameter & value \\
\hline Input source voltage (amplitude) & $320 \mathrm{~V}$ \\
\hline Source frequency & $50 \mathrm{~Hz}$ \\
\hline Switching frequency & $10 \mathrm{kHz}$ \\
\hline Simulation sampling period & $2 \mu \mathrm{s}$ \\
\hline input displacement angle & 0 \\
\hline Input filter capacitance & $8 \mu \mathrm{F}$ \\
\hline Input filter inductance & $2 \mathrm{mH}$ \\
\hline Input filter damping resistance & $60 \Omega$ \\
\hline Load inductance & $10 \mathrm{mH}$ \\
\hline Load resistance & $50 \Omega$ \\
\hline Clamp capacitance & $3 \mathrm{uF}$ \\
\hline Clamp resistance & $100 \mathrm{~K} \Omega$ \\
\hline
\end{tabular}

where $Q_{L}$ is the total energy stored in the three load inductances to transfer to the clamp in the case that the matrix converter feeds a passive load, and $i_{x}, i_{y}$ and $i_{z}$ are the rms currents of three-phase load.

\section{SimUlation RESUlts}

To test the commutation technique and clamp circuit, a three-phase to three-phase direct matrix converter with an RL load has been simulated using MATLAB Simulink. Table I illustrates the parameters of the power circuit. The converter is controlled with space vector modulation using doublesided switching pattern and one zero vector [6]. Fig. 7 shows the output voltage and current of the first phase of the output load, source voltage and current, input current before filtering and also voltage of the clamp circuit for the instant of the converter shutdown. The converter is shut down after $40 \mathrm{~ms}$ and as it can be seen before that the voltage across clamp capacitor equals the peak voltage of the input line to line voltage. The total energy stored in the load discharges in the clamp capacitor after shutting down the converter [14]. Fig. 6 shows the commutation of current between two bidirectional switches.

\section{CONCLUSIONS}

The paper reviews four-step current commutation strategy used in direct matrix converters to avoid overvoltage and overcurrent stresses on bidirectional switches. Also designing a traditional clamp circuit for a matrix converter has illustrated which feeds an RL load and is validated by MATLAB simulations. It can be concluded that the design expressions are useful to achieve safe operation of the matrix converter against over voltage spikes. 


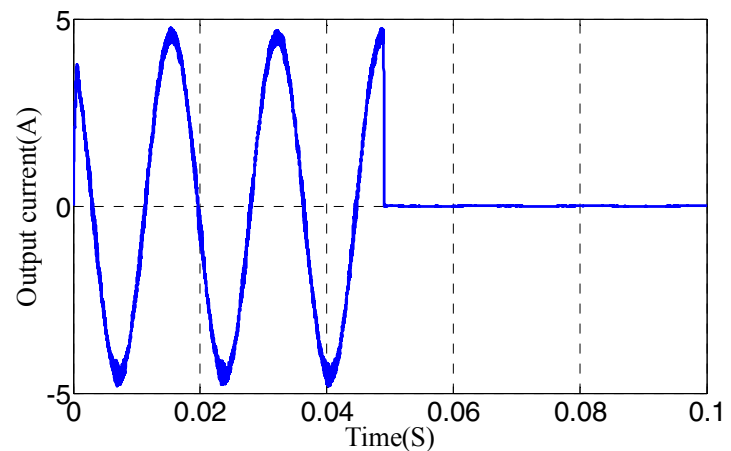

(a)

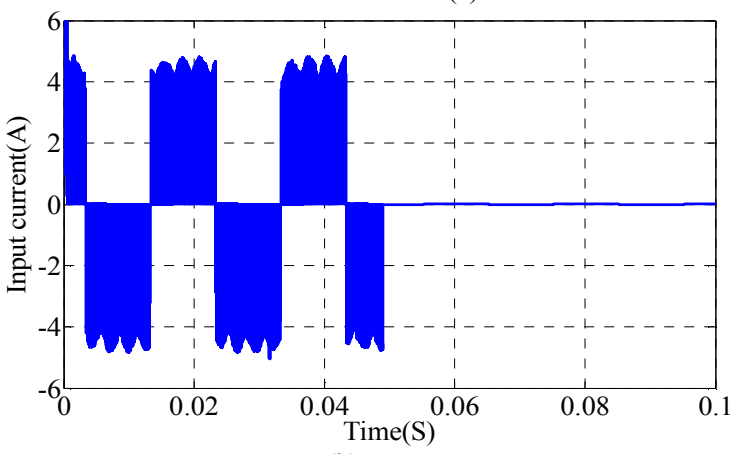

(b)

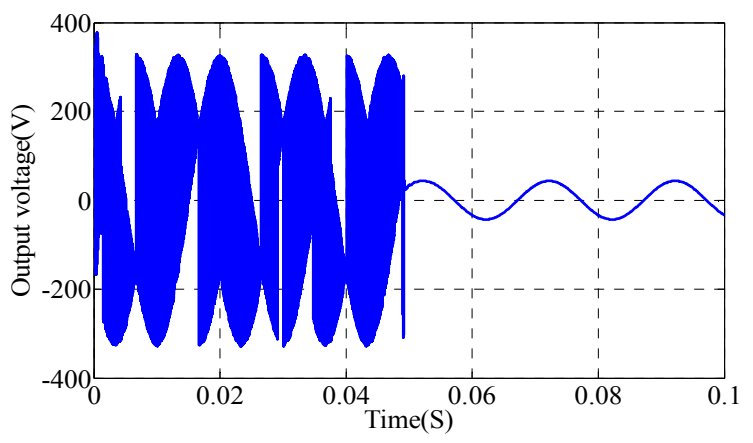

(e)

Fig. 7. Simulation of a three-phase to three-phase matrix converter in fault situation (converter shutdown) at $60-\mathrm{Hz}$ output frequency (a) output current $i_{X}(\mathrm{~b})$ source phase voltage and current $v_{S A}, i_{S A}(\mathrm{c})$ input current after the filter

$i_{A}$ (d) clamp capacitor voltage in fault instant(e) Output phase voltage $v_{X}$.

\section{REFERENCES}

[1] H. Nikkhajoei and R. Iravani, "Steady-State Model and Power Flow Analysis of Electronically-Coupled Distributed Resource Units", in IEEE Trans. on Power Delivery, vol. 22, no. 1, pp. 721-728, Jan. 2007.

[2] M. Jafari, Z. Malekjamshidi, G. Lei, T. Wang, G. Platt and J. Zhu, "Design and Implementation of an Amorphous High-Frequency Transformer Coupling Multiple Converters in a Smart Microgrid," IEEE Trans. on Ind. Electronics, vol. 64, no. 2, pp. 1028-1037, Feb. 2017.

[3] D. G. Dorrell, "Understanding and modeling of matrix converters for application in renewable energy and micro grid applications," IECON 2014 - 40th Annual Conference of the IEEE Industrial Electronics Society, Dallas, TX, 2014, pp. 4409-4415.

[4] P. Nielsen, F. Blaabjerg, J. K. Pedersen, "Space Vector Modulated Matrix Converter with Minimized Number of Switchings and a Feedfonvard Compensation of Input Voltage Unbalance", IEEE PEDES 1996, pp. 833 - 839.

[5] Ruzlaini Ghoni, Ahmed N. Abdalla, S. P. Koh, Hassan Farhan Rashag and Ramdan Razali, "Issues of matrix converters: Technical review", International Journal of the Physical Sciences Vol. 6(15), pp. 3576-3588, 4 August, 2011.

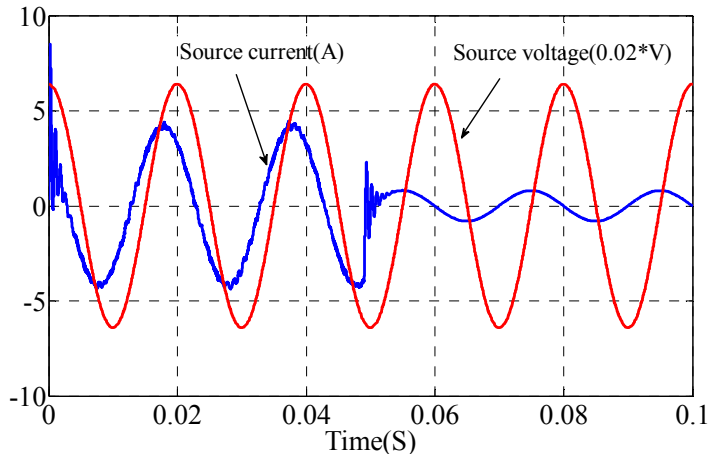

(b)

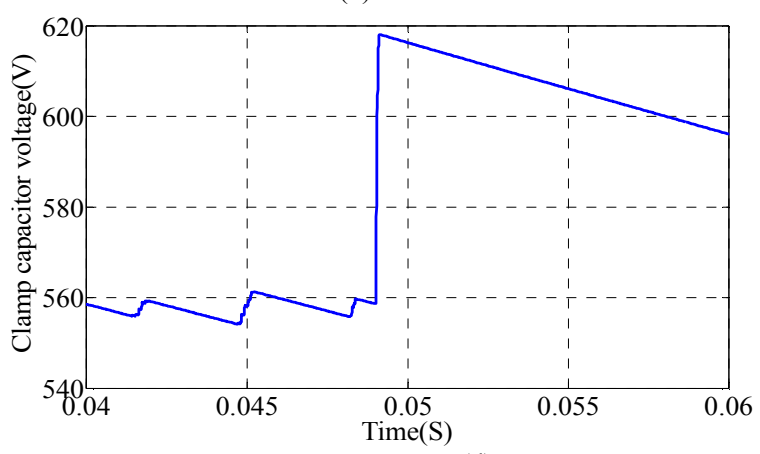

(d)

[6] D. Casadei, G. Serra, A. Tani, and L. Zarri, "Optimal use of zero vectors for minimizing the output current distortion in matrix converters," IEEE Trans. Ind. Electron., vol. 56, no. 2, pp. 326-336, Feb. 2009.

[7] J. Rodriguez, E. Silva, F. Blaabjerg, P. Wheeler, J. Clare,J. Pontt, "Matrix converter controlled with the direct transfer function approach: Analysis, modelling and simulation", International Journal of Electronics, vol. 92, 2005, pp. 63-85.

[8] Z. Malekjamshidi, M. Jafari, D. Xiao and J. Zhu, "Operation of indirect matrix converters in different SVM switching patterns", in Proc. 4th Int. Conf. on Electric Power and Energy Conversion Systems (EPECS), Sharjah, 2015, pp. 1-5.

[9] Z. Malekjamshidi, M. Jafari, D. Xiao and J. Zhu, "Analysis of direct matrix converter operation under various switching patterns", in Proc. IEEE 11th Int. Conf. on Power Electronics and Drive Systems, Sydney, NSW, 2015, pp. 630-634.

[10] M. Ziegler and W. Hofmann, "New One-Step Commutation Strategies in Matrix Converters", PEDS'01 Bali Proceedings, 2001: p. $560-564$.

[11] Burany, N., "Safe Control of Four Quadrant Switches". IEEE Conference Record of the Industrial Application Society Annual Meeting,, 1989: p. 1190-1194.

[12] Marcus Ziegler and W. Hofmann, "Semi-natural Two steps commutation strategy for Matrix Converter", PESC, Fukuoka/Japan, 1998: p. 727-731.

[13] Z.Malekjamshidi, M.Jafari, J.G.Zhu, "Analysis and Comparison of Direct Matrix Converters Controlled by Space Vector and Venturini Modulations", IEEE PEDS 2015, June 2015.

[14] P.Nielsen, F.Blaabjerg, J.. K. Pedersen, "New Protection Issues of a Matrix Converter: Design Considerations for Adjustable-Speed Drives" IEEE Trans. On Ind. App, Vol. 35, No. 5, Sep1999. 